\title{
CONTINUOUS SPINAL ANAESTHESIA WITH LEVOBUPIVACAINE IN A PATIENT WITH SEVERE AORTIC STENOSIS UNDERGOING DISTAL URETERECTOMY WITH URETERAL REIMPLANTATION
}

Ana Fernandes ${ }^{1}$, Luís Lopes ${ }^{1}$

1 - Hospital Prof. Doutor Fernando Fonseca, Anaesthesiology, Lisboa, Portugal

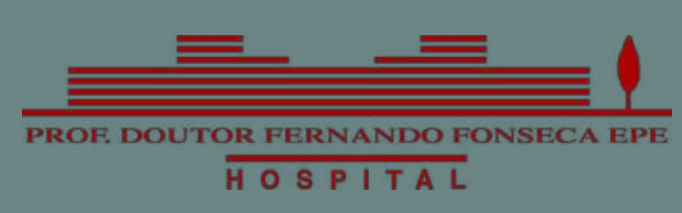

\section{Background and aims}

Severe aortic stenosis (SAS) is associated with increased morbidity and mortality during the perioperative period in patients undergoing noncardiac surgery. Continuous spinal anaesthesia (CSA) may prove advantageous in this subgroup of patients, to minimize hemodynamic changes.

\begin{abstract}
Methods
Identification: female, 88 years old, ASA IV. Co-morbidities: SAS (submitted to balloon aortic valvuloplasty one month prior), stage 4 chronic kidney disease, hypertension, type 2 diabetes and dyslipidemia.

Procedure: distal ureterectomy with ureteral reimplantation due to urothelial carcinoma (approximate duration 180 minutes).
\end{abstract}

\section{Technique}

- Standard ASA monitoring, premedication (1 mg midazolam IV) and placement of an arterial line.

- CSA - dural puncture at L3-L4 spinal level (18G Tuohy needle) and insertion of the spinal catheter. $2 \mu \mathrm{g}$ of sufentanyl and $2.5 \mathrm{mg}$ of levobupivacaine $(0.5 \%)$ were given through the catheter. After the initial dose, four additional top-ups of levobupivacaine $0.1 \%$ (1 mg each) were administered. The catheter was removed at the end of surgery.

- A peripheral noradrenaline infusion up to $8 \mu \mathrm{g} / \mathrm{min}$ to maintain MAP $>65 \mathrm{mmHg}$ was used. IV fentanyl (total $100 \mu \mathrm{g}$ ) was given in intermittent boluses throughout.

\section{Results}

The patient remained stable throughout surgery and spent the first $48 \mathrm{~h}$ of postoperative recovery in the coronary intensive care unit. The postoperative course was uneventful, and the patient was discharged on the $10^{\text {th }}$ postoperative day.

\section{Conclusions}

CSA, although unpopular, is a safe and effective anesthetic technique for the management of patients with SAS. 